Chirurgia (2021) 116: 542-553

No. 5, September - October

Copyright@ Celsius

http://dx.doi.org/10.21614/chirurgia.116.5.542

\title{
Endorectal Ultrasound in Local Recurrence of Rectal Cancer: A Systematic Review
}

\author{
Adnan AI Aloul ${ }^{1,2^{*}}$, Liviu-Ioan Șerban ${ }^{3}$, Florin Dan Ungureanu ${ }^{1,4}$ \\ 1"Titu Maiorescu” University, Faculty of Medicine, Bucharest, Romania \\ Department of General Surgery, Municipal Clinical Hospital Râmnicu Sărat, Romania \\ 3"Carol Davila" University of Medicine and Pharmacy, Bucharest, Romania \\ ${ }^{4}$ Department of General Surgery, Clinical Hospital CF 1 Witing, Bucharest, Romania
}

${ }^{*}$ Corresponding author: Adnan Al Aloul, MD, PhDc Str. Nicolae Bălcescu, No. 2 Râmnicu Sărat, Buzău, 125300 E-mail: adnanalaloul@yahoo.com
Received: 02.05 .2021 Accepted: 15.08 .2021

\section{Rezumat \\ Ultrasonografia endorectală în urmărirea recurențelor locale din cancerul de rect: o sinteză sistematică}

Recurențele locale (RL) ale cancerului de rect (CR) au o rată de supraviețuire în afara bolii de până la $50 \%$ dacă sunt diagnosticate devreme. Ultrasonografia endorectală (USER) combinată cu utilizarea tuşeului rectal sunt două metode de urmărire a pacienților ce pot fi realizate într-un cabinet de consultație. Acesta este primul studiu realizat pentru a determina acuratețea diagnostică a USER în detectarea RL din CR şi a determina dacă reprezintă o metodă de încredere în supravegherea pacienților. Trei autori au căutat independent în bazele de date MEDLINE şi ClinicalTrials.gov şi au inclus articolele originale relevante bazat pe criteriile includere/ excludere. 3220 de articole au fost identificate inițial, din care 50 au fost selectate după citirea abstractelor. 22 de articole au fost incluse în final, reprezentând 3737 de pacienți supravegheați $59,72 \pm 16,4$ luni. Bazat pe datele disponibile, sensibilitatea USER a fost $88,3 \%$ (CI 84,6 - 91,3\%), specificitatea egală cu $94,3 \%$ (CI 92,7 - 95,5\%) şi rata relativă de diagnostic a fost 271,88 (CI 76,998 - 960,04). USER a fost singura metodă care a diagnosticat RLîn $40 \pm 12 \%$ (CI $28-52 \%)$ din cazuri. Suprafața de sub curba sROC a fost $0,9723 \pm 0,131$. După tratamentul curativ al $\mathrm{CR}$ au apărut RL la $15 \pm 2,99 \%$ din pacienți. In concluzie, USER pare să fie o metodă bună şi eficientă de supraveghere a pacienților pentru depistarea RL după CR. 
Cuvinte cheie: ultrasonografie endorectală, recurența cancerului de rect, recurențe locale, supraveghere

\section{Abstract}

Local recurrence (LR) of rectal cancer (RC) has a disease-free survival rate of up to $50 \%$ if diagnosed early. Endorectal ultrasound (ERUS) is an outpatient procedure that can be used together with rectal digital examination for patient follow-up. This is the first study to determine the diagnostic test accuracy of ERUS in the detection of LR after RC and whether it is a good follow-up method. Three authors independently searched MEDLINE and ClinicalTrials.gov databases and included relevant original studies based on strict inclusion/ exclusion criteria. 3220 articles were identified. After reading the abstracts, 50 articles were selected, out of which 22 were deemed suitable for study inclusion, comprising 3737 patients, which were followed for 59,72 $\pm 16,4$ months. Based on the available data, sensitivity of ERUS was $88,3 \%$ (CI 84,6-91,3\%), specificity was $94,3 \%$ (CI 92,7-95,5\%) and diagnostic odds ratio of ERUS was 271,88 (CI 76,998 - 960,04), with ERUS being the only diagnosis method to detect LR in $40 \pm 12 \%$. Area under the curve for ERUS was 0,9723 $\pm 0,0131$. LR after curative treatment of RC in our study was $15 \pm 2,99 \%$. Concluding, ERUS seems to be a good and efficient follow-up method for diagnosing RC LR.

Key words: endorectal ultrasound, recurrent rectal cancer, local recurrence, follow-up

\section{Introduction}

Locally recurrent rectal cancer is characterised by clinical, radiological and/or pathological determination of rectal cancer recurrence in the pelvic region, following a curative treatment (1). Even though, in the last three decades, the incidence of local recurrence (LR) has dropped from 30\% to less than $10 \%$, LR still affects a large number of oncologic patients which suffer from symptoms such as: localized pelvic pain, bleeding, fistula and, ultimately, death (2). With the development of chemotherapy, radiotherapy and "watch-and-wait" strategy, the early detection of LR is of utmost importance in the follow-up of rectal cancer patients, owing to better survival and better functional outcomes (3). Early LR can be treated either by salvage surgery or by local excision depending on the stage of the LR at diagnosis, leading to a disease-free survival rates ranging between
20 to 50 percent (4-8). Thus, a good follow-up strategy has an important role in the management of the patient post-treatment.

Endorectal ultrasound or transrectal ultrasound (ERUS/ TRUS) is an outpatient procedure that uses an ultrasound probe introduced in the rectal lumen in order to visualise the rectal wall and its layers. Compared with MRI, CT or digital examination only, ERUS has been shown to be a better choice in pre-operative staging of local rectal cancer to determine local tumour invasion (9). In the same meta-analysis (9), neither of the procedures had a higher accuracy at staging lymph node involvement. Even though, there is still no agreement on what imaging method has the highest accuracy in detecting early LR, digital examination combined with ERUS makes it an easy, safe and cheap method to follow-up with patients.

The aim of this systematic review is to determine the diagnostic test accuracy of 
ERUS/ TRUS in the detection of LR after rectal cancer and if it should be trusted as good follow-up method.

\section{Material and Method}

\section{Literature search}

A comprehensive systematic literature search was performed in the MEDLINE PubMed database and ClinicalTrials.Gov to identify published articles in English or enrolled clinical trials based on human subjects. The work done for this article was in accordance to the PRISMA 2020 Checklist. Relevant articles for follow-up after rectal cancer and the use of ERUS/ TRUS in the diagnosis of LR after rectal cancer were included. The MEDLINE search spanned between January 1986 and January 2021 and included the MeSH (Medical SubHeadings) terms: "transrectal ultrasound", "transrectal ultrasonography", "transrectal echography", "endorectal ultrasound", "endorectal ultrasonography", "endorectal echography" AND "rectal cancer", "rectal neoplasm", "colorectal cancer", "colorectal neoplasm". To identify additional relevant reference, the reference list of included articles was checked manually for other studies of importance. For ClinicalTrials.Gov there were two independent broad searches based on a simple MeSH term: "recurrent rectal cancer" and "endorectal ultrasound".

\section{Data Extraction}

The studies were reviewed by two authors working independently (AA; LIS;) There was a two-parts process consisting of reviewing the titles and abstracts of all articles in order to include them to a full-text review and reading the final full-text analysis of the selected articles, eliminating from the review the ones that do not follow our criteria. In order to assure a $90 \%$ inter-reviewer similarity, the two authors swapped and compared the databases to check variables. Whenever it was necessary, a third reviewer (FDU) was called upon to decide including or excluding studies if the first two did not agree. The authors extracted the following data whenever it was available: author, year, funding, study design, location, number of centres, type of study (therapeutic or diagnostic), true positives, false positives, false negatives, true negatives, number of patients, percentage of patients diagnosed by ERUS/ TRUS alone, local recurrence rate, time of follow-up (FU) (maximum time period mentioned for each study), NCT registration and conclusion.

\section{Study Selection}

All included studies are in-line with the following inclusion criteria: (a) either a retrospective, prospective or randomized controlled trial; (b) more than 25 patients; (c) including follow-up of rectal cancer or colorectal cancer patients or diagnosis of LR using ERUS/ TRUS; (d) full-text available in English language. All articles that were: (a) reviews, editorial letters, animal studies, treatment protocols, diagnosis protocols, epidemiology studies or (b) studies that did not include ERUS/TRUS were excluded. Some articles that followed all of the above criteria were excluded because they did not provide sufficient data about the follow-up of patients and no data could be extracted regarding diagnosis accuracy or the use of ERUS/ TRUS.

\section{Statistical Analysis}

Whenever possible, the data was extracted directly from the published articles. The measured outcomes were sensitivity, specificity, diagnostic odds ratio (DOR), area under the curve (AUC), percentage of LR diagnosed only by ERUS/ TRUS and local recurrence rate. Authors define sensitivity as the probability that ERUS/ TRUS will be positive in local recurrence cases and specificity as the probability that ERUS/ TRUS result will be negative in a case without local recurrence (10). DOR is defined as a single number that describes how many times higher are the chances of obtaining an ERUS/ TRUS positive result in $L R$ than in a patient without $L R$ 
and it summarizes the diagnostic accuracy of ERUS. We also used Youden's Index as a general index of ERUS/TRUS accuracy and was calculated as sensitivity + specificity -1 (10). Summary receiver operating characteristics (sROC) and AUC were developed and calculated. In general, an AUC close to 1 means ERUS/TRUS is the best test for LR after $\mathrm{RC}$ and a value close to 0.5 would mean ERUS/ TRUS is a poor test for LR after RC. Q* is the intercept of the sROC and antidiagonal line through the unit square. $\mathrm{Q}^{*}$ is used to indicate the overall accuracy of a test by comparing the case if sensitivity and specificity are the same, resulting that the closer the $Q^{*}$ to 1 , the better the accuracy. In order to take into consideration, the inconsistency and heterogeneity of studies between the pooled time intervals we used $\mathrm{I}^{2}$ statistics to calculate the percentage of variation across studies that is due to heterogeneity rather than chance (11, 12) with values closer to $0 \%$ meaning the confidence intervals of data across studies closely overlaps, whereas a value larger than $50 \%$ means there is low overlap between confidence intervals among studies. Usually, values of $\mathrm{I}^{2}$ have $25 \%, 50 \%$ and $75 \%$ cut-offs for low, moderate and high inconsistency. Authors also looked at likelihood ration that ERUS/ TRUS would be expected in a patient with LR compared to the likelihood of the same result to be seen in a patient without LR (10). Confidence intervals (CI) were set at $95 \%$. Authors also tried to explore sources of heterogeneity in the studies using MosesShapiro-Littenberg meta-regression (multivariate regression of the summary estimate DOR) (13) method of Weighted Least Squares by inverse variation (14). Data analysis was performed using RevMan 5.4.1 (The Nordic Cochrane Centre, Copenhagen, Denmark), MetaDisc 1.4 (Unit of Clinical Biostatistics Team of the Ramon y Cajal Hospital, Madrid, Spain) and IBM SPSS Statistics v27 (Chicago, Illinois, USA).

\section{Results}

After the search was performed there were
2806 articles identified from PubMed/Medline database and 414 clinical trials identified on ClinicalTrials.gov (363 trials for "recurrent rectal cancer" and 51 trials for "endorectal ultrasound"). After reading the abstracts and extensively cross-checked reference list of selected articles, authors selected 50 articles for full-text analysis and no clinical trial on NCT database was found to study the follow-up of rectal cancer with ERUS/ TRUS or the diagnosis of LR after rectal cancer using ERUS/TRUS. Of the 50 articles selected, authors considered eligible for study inclusion only 22 articles. Reasons for not including studies were: (a) 11 articles were not available in English; (b) 6 articles considered recurrent rectal cancer an exclusion criteria; (c) 5 articles had no clear data to assess follow-up method; (d) for 3 articles authors did not succeed in finding a full-text article; (e) 1 article had fewer than 25 patients in follow-up population; (f) 1 article was studying endoscopic ultrasonography; (g) 1 article did not differentiate among pelvic tumours (see Fig. 1);

418 data sets were retrieved from the 22 articles. $72.72 \%$ of the articles ( 16 articles) had a prospective study design, $27.28 \%$ had a retrospective study design (6 articles) and no article was a randomized controlled trial. Almost all articles were unicentric, with the exception of one article (15). Only $9.09 \%$ of studies (2 articles) $(16,17)$ acknowledged their funding, both of them having no conflict of interest. The main focus of the included articles was follow-up (77.27\%; 17 articles) and not treatment $(21.74 \% ; 5$ articles). There were 3737 patients included in our database of 22 articles. Patients were followed for a maximum of $59.72 \pm 16.4$ (CI $43.3-76.1$ ) months (see Table 1). In agreement with our search of literature in ClinicalTrials.gov, only one of the articles had a protocol published in a clinical trial registry (DRK) (16).

All included articles used ERUS/ TRUS as a follow-up method as per our inclusion criteria. Further analysis of the literature for follow-up method included in at least one of the visits showed the following: digital examination (90.09\%; 20 articles), biomarkers 


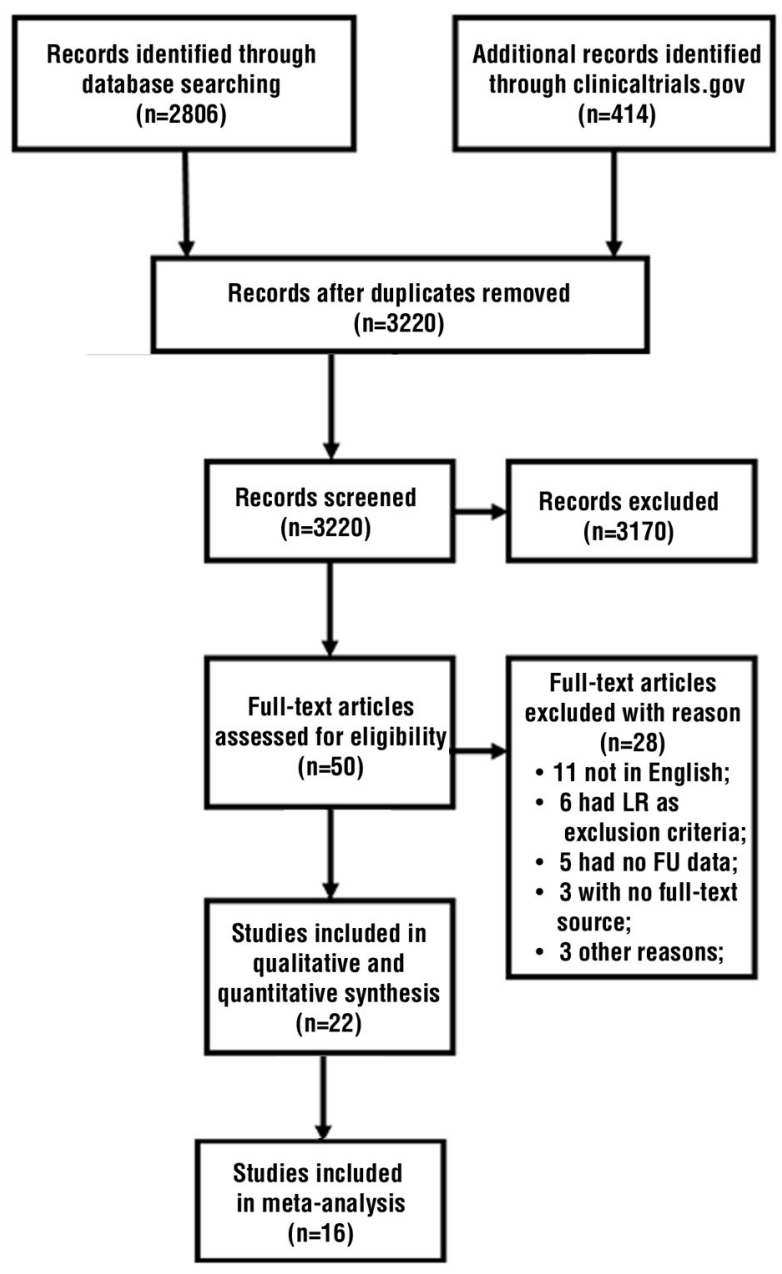

Figure 1. Flow diagram of the process of inclusion and exclusion of studies for this systematic review

(primarily CAE) (59.09\%; 13 articles), MRI or CT (59.09\%; 13 articles), colonography (50\%; 11 articles) and PET-CT or scintigraphy (4.54\%; 1 article) (see Table 2).

Only 16 articles had available data for meta-analysis. Sensitivity of ERUS/TRUS calculated from the pooled studies was $88.3 \%$ (CI 84.6-91.3\%) with an inconsistency among studies of $\mathrm{I}^{2}=68.3 \%$ (see Table 4 and Fig. 2). Specificity of ERUS/ TRUS was calculated for the selected studies at $94.3 \%$ (CI $92.7-95.5 \%)$ with an inconsistency among studies of $\mathrm{I}^{2}=$ 90.0\% (Table 3 and Fig. 2). Positive likelihood ratio is $21.184(\mathrm{CI} 8.265-54.298)\left(\mathrm{I}^{2}=91.8 \%\right)$ meaning it was approximatively 21 times more likely to have LR if suspected findings arise during ERUS/ TRUS and negative likelihood ratio is $0.134(\mathrm{CI} 0.082-0.22)\left(\mathrm{I}^{2}=\right.$ $50.6 \%$ meaning that only $13 \%$ of suspected lesions detected with ERUS/TRUS were of nonmalign origin (see Table 5, Fig. 3). DOR of ERUS/ TRUS for the pooled studies was 271.88 (CI 76.998-960.04) $\left(I^{2}=69.6 \%\right)$ with an estimate variance for between-study of 4.0238 (see Table 6, Fig. A). ERUS/ TRUS was the only diagnosis method to detect LR in $40 \pm 12 \%$ (CI $28-52 \%$ ) of detected LR (data available in 14 articles). The calculated rate of local recurrence after curative treatment of rectal cancer in our study was $15 \pm 2.99 \%$ (CI $12-18 \%$ ) (data available from 22 articles) (see Table 3).

Developing sROC Curve (1-specificity), calculating AUC and $\mathrm{Q}^{*}$ authors obtained a value for $\mathrm{AUC}=0.9723 \pm 0.0131$ and $\mathrm{Q}^{*}=$ $0.9235 \pm 0.0219$ (see Fig. 5). This value and the aspect of sROC curve suggest there is no diagnostic threshold effect in our analysis (13). To further investigate this hypothesis, Spearman correlation coefficient between sensitivity and specificity was calculated using Moses's model (18) and it is equal to $0.425(\mathrm{p}=0.101)$ which proves that there is no threshold effect.

In order to investigate for sources of heterogeneity (14), local recurrence rate and the period of follow-up were used in a metaregression using extended Moses's model (18) for covariates. The $\mathrm{p}$-value of this analysis was 0.6122 for local recurrence rate and 0.5132 for follow-up period with CI including a 0 value for RDOR (relative DOR). This translates that the observed heterogeneity is not due to these specific covariates. Table 7 summarises the results of this diagnostic test accuracy metaanalysis on ERUS/ TRUS as a method of surveillance for LR after RC.

The authors have analysed whether the included studies had reached a positive, negative or neutral/ undecided outcome. Of the 17 articles that looked at ERUS/ TRUS as follow-up method, $76.47 \%$ of studies (13 articles) reached a positive outcome, meaning that ERUS/ TRUS was considered a good follow-up method, $23.52 \%$ of studies (4 articles) could not decide or did not have confidence in ERUS/ TRUS as follow-up 
Table 1. Study design model, number of centres, type of study, number of patients and maximum length of follow-up (months) for the 22 included studies

\begin{tabular}{|c|c|c|c|c|c|}
\hline Article & $\begin{array}{l}\text { Design } \\
\text { (retrospective, prospective, } \\
\text { randomized controlled trials); }\end{array}$ & $\begin{array}{c}\text { No. Centres } \\
\text { (unicentric, multicentric); }\end{array}$ & $\begin{array}{l}\text { Group } \\
\text { (Therapy study, } \\
\text { Follow-up study) }\end{array}$ & $\begin{array}{c}\text { No. } \\
\text { Patients }\end{array}$ & $\begin{array}{l}\text { Length of FU } \\
\text { (months) }\end{array}$ \\
\hline Kwakye et al, 2019 (38) & retrospective & unicentric & Follow-up study & 114 & 178 \\
\hline Manegold et al, 2019 (16) & retrospective & unicentric & Therapy study & 88 & 60 \\
\hline Li et al, 2015 (15) & prospective & multicentric & Therapy study & 122 & 108 \\
\hline Park et al, 2015 (39) & retrospective & unicentric & Therapy study & 593 & 84 \\
\hline Morken et al, 2006 (21) & retrospective & unicentric & Follow-up study & 525 & 56 \\
\hline Hernandez de Anda et al, 2004 (22) & prospective & unicentric & Follow-up study & 275 & 61 \\
\hline Drudi et al 2001 (24) & prospective & unicentric & Follow-up study & 43 & 60 \\
\hline Hünerbein et al, 2001 (25) & prospective & unicentric & Follow-up study & 312 & 60 \\
\hline Garcia-Aguilar et al, 2000 (4) & retrospective & uncenter & Therapy study & 82 & 98 \\
\hline Lohnert et al, 2000 (40) & prospective & unicentric & Follow-up study & 338 & 123 \\
\hline Ross et al, 1999 (41) & retrospective & unicentric & Therapy study & 272 & 50 \\
\hline Novell et al, 1997 (42) & prospective & unicentric & Follow-up study & 140 & 44 \\
\hline Rotondo et al, 1997 (43) & prospective & unicentric & Follow-up study & 62 & 26 \\
\hline Hunerbein et al, 1996 (44) & prospective & unicentric & Follow-up study & 163 & 24 \\
\hline de Gara et al, 1995 (36) & prospective & unicentric & Follow-up study & 30 & 24 \\
\hline Ramirez et al, 1994 (17) & prospective & unicentric & Follow-up study & 66 & 60 \\
\hline Romano et al, 1993 (45) & prospective & unicentric & Follow-up study & 37 & 25 \\
\hline Scialpi et al, 1993 (37) & prospective & unicentric & Follow-up study & 35 & 24 \\
\hline Dressing et al, 1990 (46) & prospective & unicentric & Follow-up study & 106 & 56 \\
\hline Beynon et al. 1989 (47) & prospective & unicentric & Follow-up study & 85 & 54 \\
\hline Mascagni et al, 1989 (48) & prospective & unicentric & Follow-up study & 120 & 15 \\
\hline Hildebrandt et al, 1986 (49) & prospective & unicentric & Follow-up study & 129 & 24 \\
\hline
\end{tabular}

method used by itself and no article reached a negative outcome, excluding ERUS/ TRUS from the follow-up protocol.

\section{Discussion}

In this systematic review authors summarized all relevant literature available to see whether ERUS/ TRUS is an efficient method of detection of LR after rectal cancer. ERUS/ TRUS was found to have a diagnostic odds ratio of almost 270 and an AUC $=0.973$ which are strong indicators that ERUS/ TRUS is a fine tool in the diagnosis of LR after RC and was the only method able to detect LR in more

Table 2. Follow-up methods included in at least one of the visits in the 22 articles included

\begin{tabular}{lcc}
\hline Follow-up method & Frequency & Percentage \\
\hline ERUS & 22 & $100 \%$ \\
\hline Digital examination & 20 & $90.09 \%$ \\
\hline CT or MRI & 13 & $59.09 \%$ \\
\hline colonography & 11 & $50.00 \%$ \\
\hline biomarkers & 13 & $59.09 \%$ \\
\hline PET CT or Scintigraphy & 1 & $4.54 \%$ \\
\hline
\end{tabular}

Table 3. Percentage of LR diagnosed only by ERUS/ TRUS and local recurrence rate for the 22 articles included

\begin{tabular}{lcc}
\hline Article & $\begin{array}{c}\text { Diagnosed only } \\
\text { by ERUS }\end{array}$ & $\begin{array}{c}\text { Local recurrence } \\
\text { rate }\end{array}$ \\
\hline Kwakye et al, 2019 (38) & $71.42 \%$ & $11.40 \%$ \\
\hline Manegold et al, 2019 (16) & NA & $5.70 \%$ \\
\hline Li et al, 2015 (15) & NA & $3.30 \%$ \\
\hline Park et al, 2015 (39) & NA & $3.90 \%$ \\
\hline Morken et al, 2006 (21) & $13 \%$ & $7.40 \%$ \\
\hline Hernandez de Anda et al, 2004 (22) & $31 \%$ & $11.63 \%$ \\
\hline Drudi et al 2001 (24) & NA & $47.05 \%$ \\
\hline Hónerbein et al, 2001 (25) & $67 \%$ & $11.53 \%$ \\
\hline Garcia-Aguilar et al, 2000 (4) & NA & $24.39 \%$ \\
\hline Lohnert et al, 2000 (40) & $22.00 \%$ & $34.30 \%$ \\
\hline Ross et al, 1999 (41) & NA & $12.70 \%$ \\
\hline Novell et al, 1997 (42) & NA & $15 \%$ \\
\hline Rotondano et al, 1997 (43) & $18 \%$ & $17.74 \%$ \\
\hline Hunerbein et al, 1996 (44) & $67 \%$ & $17 \%$ \\
\hline de Gara et al, 1995 (36) & NA & $20 \%$ \\
\hline Ramirez et al, 1994 (17) & $23 \%$ & $20 \%$ \\
\hline Romano et al, 1993 (45) & $67 \%$ & $16.20 \%$ \\
\hline Scialpi et al, 1993 (37) & NA & $9 \%$ \\
\hline Dressing et al, 1990 (46) & $33 \%$ & $12 \%$ \\
\hline Beynon et al. 1989 (47) & $14 \%$ & $25.90 \%$ \\
\hline Mascagni et al, 1989 (48) & $35 \%$ & $14 \%$ \\
\hline Hildebrandt et al, 1986 (49) & $27 \%$ & $25.50 \%$ \\
\hline Calculated values & $47.57 \pm 12$ & $15 \pm 2.99$ \\
\hline & & $(12$ to 18$)$ \\
\hline
\end{tabular}



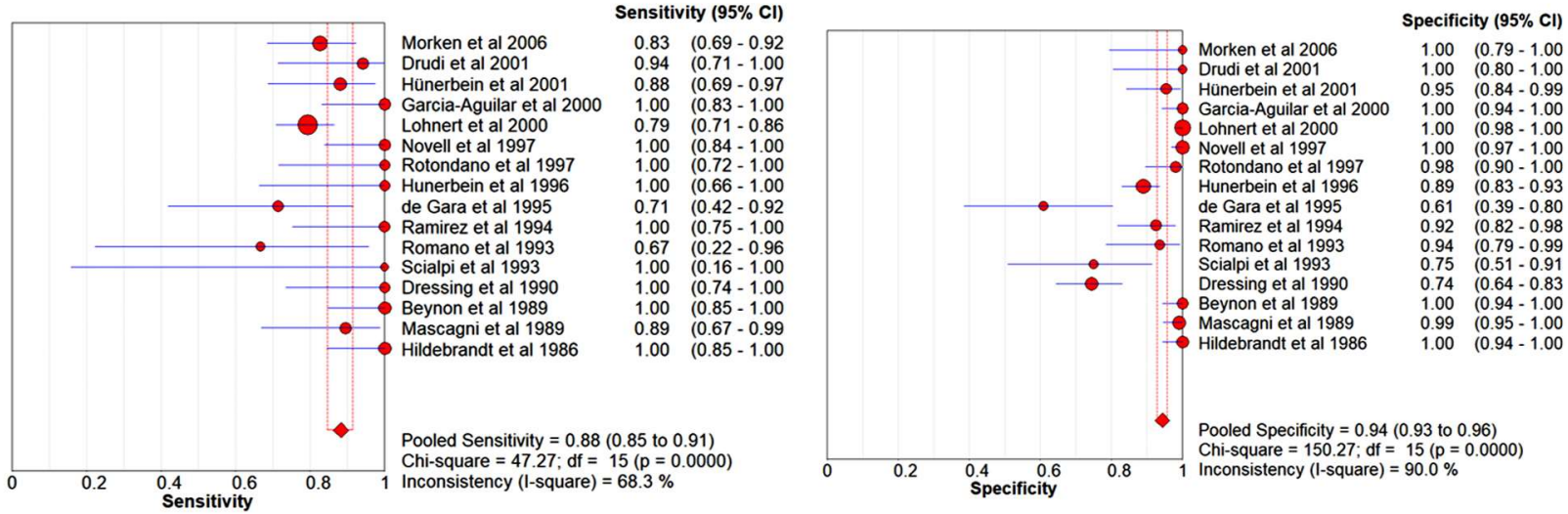

Figure 2. Forrest plots graphical representation of Sensitivity and Specificity of ERUS/ TRUS (constructed with MetaDisc 1.4)
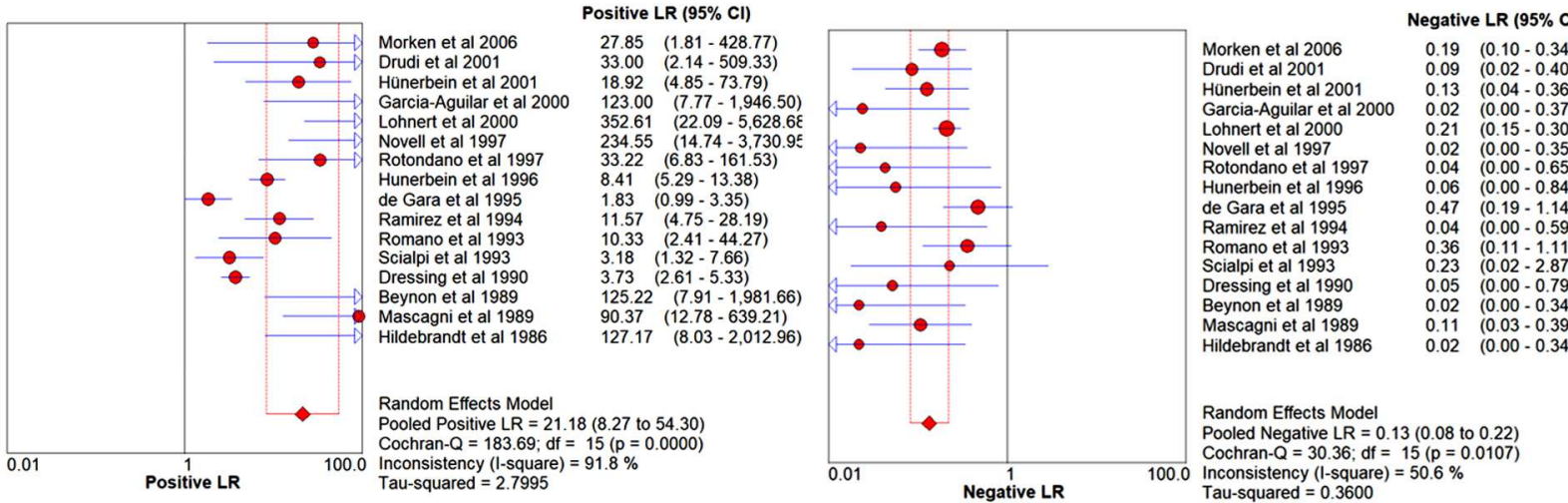

Figure 3. Forrest plots graphical representation of positive and negative likelihood of ERUS/ TRUS (generated with MetaDisc 1.4)

Table 4. Sensitivity and Specificity of ERUS/ TRUS calculated for the 16 articles included in meta-analysis

\begin{tabular}{|c|c|c|c|c|c|c|c|c|}
\hline Article & Sen. & \multicolumn{2}{|c|}{$95 \% \mathrm{Cl}$} & Spe. & \multicolumn{2}{|c|}{$95 \% \mathrm{Cl}$} & $\mathrm{TP} /(\mathrm{TP}+\mathrm{FN})$ & $\mathrm{TN} /(\mathrm{TN}+\mathrm{FP})$ \\
\hline Morken et al, 2006 [21] & 0.826 & 0.686 & -0.922 & 1.000 & 0.794 & -1.000 & $38 / 46$ & $16 / 16$ \\
\hline Drudi et al 2001 [24] & 0.941 & 0.713 & -0.999 & 1.000 & 0.805 & -1.000 & $16 / 17$ & $17 / 17$ \\
\hline Hónerbein et al, 2001 [25] & 0.880 & 0.688 & -0.975 & 0.953 & 0.842 & -0.994 & $22 / 25$ & $41 / 43$ \\
\hline Garcia-Aguilar et al, 2000 [4] & 1.000 & 0.832 & -1.000 & 1.000 & 0.942 & -1.000 & $20 / 20$ & $62 / 62$ \\
\hline Lohnert et al, 2000 [40] & 0.793 & 0.708 & -0.863 & 1.000 & 0.984 & -1.000 & $92 / 116$ & $222 / 222$ \\
\hline Novell et al, 1997 [42] & 1.000 & 0.839 & -1.000 & 1.000 & 0.969 & -1.000 & $21 / 21$ & $119 / 119$ \\
\hline Rotondo et al, 1997 [43] & 1.000 & 0.715 & -1.000 & 0.980 & 0.896 & -1.000 & $11 / 11$ & $50 / 51$ \\
\hline Hunerbein et al, 1996 [44] & 1.000 & 0.664 & -1.000 & 0.890 & 0.829 & -0.934 & $9 / 9$ & $137 / 154$ \\
\hline de Gara et al, 1995 [36] & 0.714 & 0.419 & -0.916 & 0.609 & 0.385 & -0.803 & $10 / 14$ & $14 / 23$ \\
\hline Ramirez et al, 1994 [17] & 1.000 & 0.753 & -1.000 & 0.925 & 0.818 & -0.979 & $13 / 13$ & $49 / 53$ \\
\hline Romano et al, 1993 [45] & 0.667 & 0.223 & -0.957 & 0.935 & 0.786 & -0.992 & $4 / 6$ & $29 / 31$ \\
\hline Scialpi et al, 1993 [37] & 1.000 & 0.158 & -1.000 & 0.750 & 0.509 & -0.913 & $2 / 2$ & $15 / 20$ \\
\hline Dressing et al, 1990 [46] & 1.000 & 0.735 & -1.000 & 0.745 & 0.644 & -0.829 & $12 / 12$ & $70 / 94$ \\
\hline Beynon et al. 1989 [47] & 1.000 & 0.846 & -1.000 & 1.000 & 0.943 & -1.000 & $22 / 22$ & $63 / 63$ \\
\hline Mascagni et al, 1989 [48] & 0.895 & 0.669 & -0.987 & 0.990 & 0.946 & -1.000 & $17 / 19$ & $100 / 101$ \\
\hline Hildebrandt et al, 1986 [49] & 1.000 & 0.846 & -1.000 & 1.000 & 0.944 & -1.000 & $22 / 22$ & $64 / 64$ \\
\hline $\begin{array}{c}\text { Pooled } \\
\text { Sensitivity \& Specificity }\end{array}$ & 0.883 & 0.846 & -0.913 & 0.943 & 0.927 & -0.955 & $\begin{array}{l}\mathbf{l}^{2}= \\
\mathbf{l}^{2}=\end{array}$ & $\begin{array}{l}\text { for Sen. } \\
\text { for Spe. }\end{array}$ \\
\hline
\end{tabular}


Table 5. Summary of positive and negative likelihood ratio of ERUS/ TRUS calculated for the 16 articles included in meta-analysis

\begin{tabular}{|c|c|c|c|c|c|c|c|}
\hline Article & $\mathrm{LR}+$ & $95 \% \mathrm{CI}$ & $\%$ Weight & LR- & & $\%$ Cl & $\%$ Weight \\
\hline Morken et al, 2006 (21) & 27.851 & $1.809-428.77$ & 4.86 & 0.186 & 0.101 & -0.344 & 13.90 \\
\hline Drudi et al 2001 (24) & 33.000 & $2.138-509.33$ & 4.86 & 0.086 & 0.018 & -0.397 & 6.55 \\
\hline Hünerbein et al, 2001 (25) & 18.920 & $4.851-73.791$ & 7.03 & 0.126 & 0.043 & -0.365 & 9.73 \\
\hline Garcia-Aguilar et al, 2000 (4) & 123.00 & $7.772-1946.5$ & 4.82 & 0.024 & 0.002 & -0.371 & 2.75 \\
\hline Lohnert et al, 2000 (40) & 352.61 & $22.089-5628.7$ & 4.81 & 0.210 & 0.148 & -0.298 & 16.23 \\
\hline Novell et al, 1997 (42) & 234.55 & $14.745-3731.0$ & 4.81 & 0.023 & 0.001 & -0.354 & 2.75 \\
\hline Rotondo et al, 1997 (43) & 33.222 & $6.833-161.53$ & 6.68 & 0.043 & 0.003 & -0.647 & 2.80 \\
\hline Hunerbein et al, 1996 (44) & 8.414 & $5.293-13.377$ & 8.08 & 0.056 & 0.004 & -0.841 & 2.82 \\
\hline de Gara et al, 1995 (36) & 1.825 & $0.994-3.353$ & 7.96 & 0.469 & 0.193 & -1.144 & 11.24 \\
\hline Ramirez et al, 1994 (17) & 11.571 & $4.750-28.187$ & 7.67 & 0.039 & 0.003 & -0.593 & 2.78 \\
\hline Romano et al, 1993 (45) & 10.333 & $2.412-44.272$ & 6.88 & 0.356 & 0.114 & -1.109 & 9.16 \\
\hline Scialpi et al, 1993 (37) & 3.182 & $1.322-7.659$ & 7.69 & 0.226 & 0.018 & -2.872 & 3.12 \\
\hline Dressing et al, 1990 (46) & 3.728 & $2.606-5.333$ & 8.14 & 0.052 & 0.003 & -0.787 & 2.79 \\
\hline Beynon et al. 1989 (47) & 125.22 & $7.912-1981.7$ & 4.82 & 0.022 & 0.001 & -0.340 & 2.75 \\
\hline Mascagni et al, 1989 (48) & 90.368 & $12.776-639.21$ & 6.08 & 0.106 & 0.029 & -0.394 & 7.89 \\
\hline Hildebrandt et al, 1986 (49) & 127.17 & $8.035-2013.0$ & 4.82 & 0.022 & 0.001 & -0.340 & 2.75 \\
\hline Pooled LR+ & 21.184 & $8.265-54.298$ & Pooled LR- & 0.134 & 0.082 & -0.220 & $\begin{array}{c}I^{2}=\mathbf{9 1 . 8} \% \text { for LR+ } \\
\text { and } \\
I^{2}=50.6 \% \text { for LR- }\end{array}$ \\
\hline
\end{tabular}

than $30 \%$ of instances. This results are in agreement with other systematic reviews and meta-analysis $(9,19,20)$ which looked at ERUS /TRUS alone or in comparison with other imaging methods for preoperative staging. As of our knowledge, this is the first systematic review to focus on the effectiveness of ERUS/ TRUS to diagnose LR after rectal cancer treatment. Our review has looked at the past 35 years of published literature in this area. The interest for this area changed over time, with the field starting to grow in the late 1980's, reaching a peak of research in the 1990's and a steady decrease to today. Most of the articles included in our study (10 articles) were published between 1991 and 2000 by either German or Italian research groups. In compliance with this remark, only one article had its

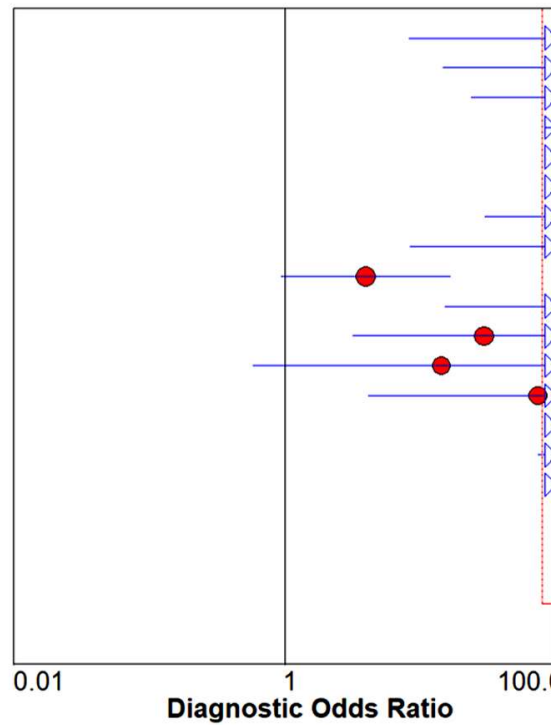

Morken et al 2006

Drudi et al 2001

Hünerbein et al 2001

Garcia-Aguilar et al 2000

Lohnert et al 2000

Novell et al 1997

Rotondano et al 1997

Hunerbein et al 1996

de Gara et al 1995

Ramirez et al 1994

Romano et al 1993

Scialpi et al 1993

Dressing et al 1990

Beynon et al 1989

Mascagni et al 1989

Hildebrandt et al 1986

Random Effects Mode

Pooled Diagnostic Odds Ratio $=271.88(77.00$ to 960.04$)$

Cochran- $Q=49.38 ; d f=15(p=0.0000)$

Inconsistency (I-square) $=69.6 \%$

Tau-squared $=4.3324$

\section{Diagnostic OR $(95 \% \mathrm{Cl})$}

149.47 (8.14 - 2,743.52)

$385.00(14.62-10,135.11)$

150.33 (23.34 - 968.28)

$5,125.00 \quad(98.53-266,582.83)$

$1,680.10 \quad(101.11-27,918.55)$

$10,277.00 \quad(198.53-532,002.1$

$774.33 \quad(29.61-20,253.01)$

$149.29 \quad(8.32-2,678.10)$

$3.89(0.93-16.26)$

$297.00(15.04-5,865.34)$

$29.00 \quad(3.15-267.37)$

$14.09(0.58-341.70)$

$71.94 \quad(4.10-1,260.99)$

$5,715.00 \quad(110.12-296.609 .97)$

$850.00 \quad(72.99-9,898.63)$

$5,805.00 \quad(111.86-301,245.22)$

Figure 4. Forrest plots graphical representation Diagnostic Odds R of ERUS/ TRUS (generated with MetaDisc 1.4) 


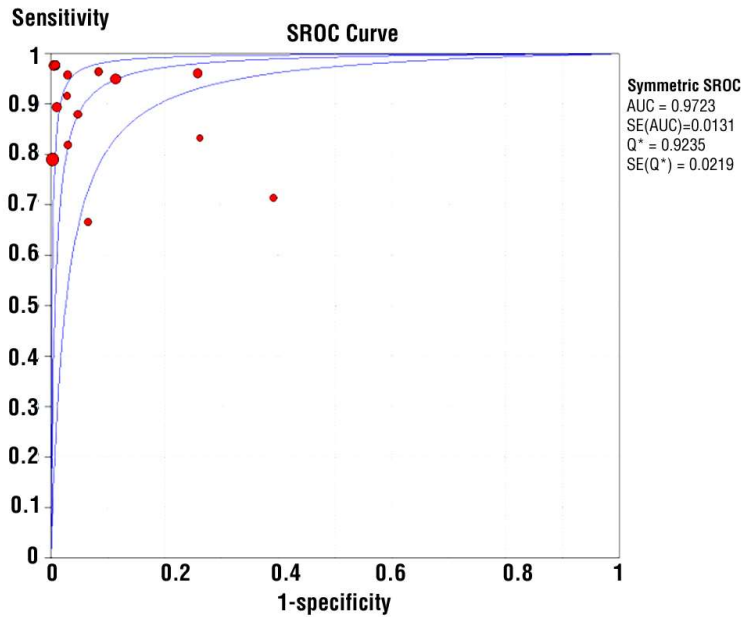

Figure 5. Summary receiver operating characteristics curve for ERUS/ TRUS (generated with MetaDisc 1.4).

protocol published in a clinical trial registry and no randomized control study was conducted to select a follow-up protocol that is safe and economic, leaving this area of interest not very accurate or with low degree of confidence. This was caused in part by the immense effort health systems put into treating patients with LR, using all available resources at hand.

As the technological advancement took place, we have remarked some patterns that are not properly expressed in numeric form. The rate of LR was higher before 2000, rang- ing between 20 to 30 percent, whereas after 2001, it dropped to around 10 percent. Even if the ultrasound resolution and image quality raised over the past three decades, this was not shown in the effectiveness reported by authors, with a slight drop to around $70 \%$ in the 2000's. This might be due to the eagerness to adapt this technique in the early 1980's and 1990's, being less time consuming and cheaper. However, the confidence in ERUS/ TRUS as a method of follow-up for LR raised in the past 20 years, with studies investigating follow-up protocols considering it a good option (21-25). Nowadays, ultrasound probes are able to create 3D reconstructions $(26,27)$, have higher image resolution and are available in most office settings, leading to a fast follow-up method when combined with digital examination. A recent study (28), showed that $52 \%$ of American radiation oncologists consider themselves a high utilizers of ERUS/ TRUS, using it in at least $75 \%$ of patients. It is important to take into consideration that our study has looked at LR and cited literature on rectal cancer staging that mentions that ERUS/ TRUS is an efficient method in assessing $\mathrm{T}$-stage and not $\mathrm{N}$-stage, where it was shown to not be reliable, especially after neoadjuvant treatment $(19,29)$.

In the published literature, ERUS/ TRUS

Table 6. Diagnostic Odds Ratio of ERUS/ TRUS calculated for the 16 articles included in meta-analysis

\begin{tabular}{|c|c|c|c|}
\hline Article & DOR & $95 \% \mathrm{Cl}$ & $\%$ Weight \\
\hline Morken et al, 2006 (21) & 149.47 & $8.143-2743.5$ & 6.34 \\
\hline Drudi et al 2001 (24) & 385.00 & $14.625-10135.1$ & 5.82 \\
\hline Hünerbein et al, 2001 (25) & 150.33 & $23.340-968.28$ & 7.91 \\
\hline Garcia-Aguilar et al, 2000 (4) & 5125.0 & $98.527-266582.8$ & 4.93 \\
\hline Lohnert et al, 2000 (40) & 1680.1 & $101.11-27918.5$ & 6.49 \\
\hline Novell et al, 1997 (42) & 10277.0 & $198.53-532002.1$ & 4.94 \\
\hline Rotondo et al, 1997 (43) & 774.33 & $29.605-20253.0$ & 5.83 \\
\hline Hunerbein et al, 1996 (44) & 149.29 & $8.322-2678.1$ & 6.37 \\
\hline de Gara et al, 1995 (36) & 3.889 & $0.930-16.255$ & 8.52 \\
\hline Ramirez et al, 1994 (17) & 297.00 & $15.039-5865.3$ & 6.23 \\
\hline Romano et al, 1993 (45) & 29.000 & $3.145-267.37$ & 7.38 \\
\hline Scialpi et al, 1993 (37) & 14.091 & $0.581-341.70$ & 5.94 \\
\hline Dressing et al, 1990 (46) & 71.939 & $4.104-1261.0$ & 6.41 \\
\hline Beynon et al. 1989 (47) & 5715.0 & $110.12-296610.0$ & 4.94 \\
\hline Mascagni et al, 1989 (48) & 850.00 & 72.990 - 9898.6 & 7.02 \\
\hline Hildebrandt et al, 1986 (49) & 5805.0 & $111.86-301245.2$ & 4.94 \\
\hline Pooled DOR & 271.88 & $76.998-960.04$ & $I^{2}=69.6 \%$ for DOR \\
\hline
\end{tabular}


Table 7. Summary of the results of DTA meta-analysis for ERUS/ TRUS

\begin{tabular}{l|c|c|c}
\hline \multirow{2}{*}{} & \multicolumn{3}{|c}{ ERUS/ TRUS } \\
\cline { 2 - 4 } & & \multicolumn{3}{|c}{ Heterogeneity } \\
\hline DOR & $271.88(76.998-960.04)$ & $69.6 \%$ & P value \\
\hline Sensitivity & $0.883(0.846-0.913)$ & $68.3 \%$ & 0.0000 \\
\hline Specificity & $0.943(0.927-0.955)$ & $90.0 \%$ & 0.0000 \\
\hline Positive LR & $21.184(8.265-54.298)$ & $91.8 \%$ & 0.0000 \\
\hline Negative LR & $0.136(0.082-0.220)$ & $50.6 \%$ & 0.0000 \\
\hline Younden's Index & 0.82 & \multicolumn{2}{|c}{ NA } \\
\hline
\end{tabular}

was researched for errors and problems that might lead to wrong diagnosis and to assess the level of difficulty of this technique. The evidence in literature suggests that ERUS/ TRUS is a method that has a fast learning curve, inter-operator differences are minimal, errors are manageable if discussed and it can be performed by practicians with ranging skills and experience (30-35).

From the 28 articles that we did not include in our data analysis after the initial search, the outcomes where in favour of ERUS/ TRUS as a method of rectal cancer staging or follow-up after rectal cancer, but due to our inclusion criteria they were not eligible for further study.

One of the main limitations of this study is the heterogeneity among articles included in the meta-analysis and the use of only published data available. As mentioned before, data for ERUS/ TRUS use in the diagnosis of LR after RC spans over the last four decades, with technology, interests in the field and data included in the published articles greatly varying. This led to studies with $100 \%$ specificity and sensitivity, whereas other studies focusing on needleguided biopsy emphasizing the role of this more invasive technique in favour of classical ERUS/ TRUS. Another confounding factor was that some studies reported the number of procedures done and the majority focused on the number of patience and the number of LR. The studies led by de Gara et al. in 1995 (36) and Scialpi et al. in 1993 (37) are two of the main outliers in our group of articles and this might be caused by the gap that was created between the advances gained by CT and MRI in favour of US technology in the beginning of the 90's. There is a change of focus in the literature that has been highlighted by our meta-analysis, recent studies published on ERUS/ TRUS used in the surveillance of LR focused on the treatment of primary rectal cancer and did not offer sufficient information for our meta-analysis. Another limitation of the current study is that authors have also looked only at Medline database and ClinicalTrials.gov registry, whereas, a future, more in-depth study should search in all available databases (BIOSIS, Scopus, WOS, Cochrane, etc.). We did not register this review in a prospective registry for systematic reviews on human studies.

We advise in favour of a multicentric randomized control trial to look for the best imaging method of follow-up for rectal cancer patients, taking into consideration patients treated with chemoradiotherapy before and/ or after the surgical treatment, period of follow-up and a cost-efficiency analysis.

\section{Conclusion}

Based on the results of this systematic review of literature, ERUS/ TRUS seems to be an efficient follow-up method for diagnosing locally recurrent rectal cancer. It is able to detect before other imaging techniques more than a third of LR, can be done in an outpatient setting and together with digital examination has a high accuracy. It is a reproductible follow-up method preferred by 
practitioners, has manageable technique errors and a fast-learning curve.

\section{Author Contribution}

$\mathrm{AA}$ is the main author of this study, AA designed the research, AA and LIS collected and analysed the data. FDU contributed substantially by critical revision. AA and LIS wrote the manuscript. The manuscript has been approved by all authors.

\section{Conflict of Interest}

The authors have no conflict of interest to declare. None of the authors received financial support or had any institutional or other relationships that might lead to bias for this study. LIS is the recipient of a scholarship from SOFMEDICA GROUP for his educational achievements.

\section{Funding}

This study had no funding.

\section{References}

1. Guillem JG, Chessin DB, Cohen AM, Shia J, Mazumdar M, Enker W, et al. Long-term oncologic outcome following preoperative combined modality therapy and total mesorectal excision of locally advanced rectal cancer. Ann Surg. 2005;241(5):829-36; discussion 836-8.

2. Ganeshan D, Nougaret S, Korngold E, Rauch GM, Moreno CC. Locally recurrent rectal cancer: what the radiologist should know. Abdom Radio (NY). 2019;44(11):3709-3725.

3. Tytherleigh MG, Warren BF, Mortensen NJMC. Management of early recta cancer. Br J Surg. 2008:95(4):409-23.

4. Mellgren A, Sirivongs P, Rothenberger DA, Madoff RD, García-Aguilar J. Is local excision adequate therapy for early rectal cancer? Dis Colon Rectum. 2000;43(8):1064-71; discussion 1071-4

5. Weiser MR, Landmann RG, Douglas Wong W, Shia J, Guillem JG, Temple LK, et al. Surgical salvage of recurrent rectal cancer after transanal excision. Dis Colon Rectum. 2005:48(6):1169-75.

6. Friel CM, Cromwell JW, Marra C, Madoff RD, Rothenberger DA, GarciaAguílar J. Salvage radical surgery after failed local excision for early recta cancer. Dis Colon Rectum. 2002;45(7):875-9.

7. Chakravarti A, Compton CC, Shellito PC, Wood WC, Landry J, Machuta SR, et al. Long-term follow-up of patients with rectal cancer managed by local excision with and without adjuvant irradiation. Ann Surg. 1999;230(1):49-54

8. Paty PB, Nash GM, Baron P, Zakowski M, Minsky BD, Blumberg D, et al Long-term results of local excision for rectal cancer. Ann Surg. 2002; 236(4):522-29; discussion 529-30.

9. Bipat S, Glas AS, Slors FJM, Zwinderman AH, Bossuyt PMM, Stoker J. Rectal cancer: local staging and assessment of lymph node involvement with endoluminal US, CT, and MR imaging - a meta-analysis. Radiology. 2004:232(3):773-83

10. Mendzhul MI, Bobrovnik SA, Lysenko TG, Shved AD. Cochrane Handbook for Systematic Reviews of Diagnostic Test Accuracy. Cochrane Collab. 2010;37(1):73-79

11. Grant J, Hunter A. Measuring inconsistency in knowledgebases. J. Intell. Inf.
Syst. 2006;27(2):159-184

12. Higgins JPT, Thompson SG. Quantifying heterogeneity in a meta-analysis. Stat Med. 2002;21(11):1539-58

13. Devillé WL, Buntinx F, Bouter LM, Montori VM, de Vet HCW, van der Windt DAWM, et al. Conducting systematic reviews of diagnostic studies. BMC Med Res Methodol. 2002:2:9.

14. Lijmer JG, Bossuyt PMM, Heisterkamp SH. Exploring sources of heterogeneity in systematic reviews of diagnostic tests. Stat Med. 2002;21(11): 1525-37.

15. Li J, Liu H, Yin J, Liu S, Hu J, Du F, et al. Wait-and-see or radical surgery for rectal cancer patients with a clinical complete response after neoadjuvant chemoradiotherapy: A cohort study. Oncotarget. 2015;6(39):42354-61.

16. Manegold P, Taukert J, Neeff $H$, Fichtner-Feigl S, Thomusch 0 . The minimum distal resection margin in rectal cancer surgery and its impact on local recurrence - A retrospective cohort analysis. Int J Surg. 2019;69: 77-83.

17. Ramirez JM, Mortensen NJ, Takeuchi N, Humphreys MM. Endoluminal ultrasonography in the follow-up of patients with rectal cancer. Br J Surg. 1994;81(5):692-4.

18. Moses LE, Shapiro D, Littenberg B. Combining independent studies of a diagnostic test into a summary roc curve: Data-analytic approaches and some additional considerations. Stat Med. 1993;12(14):1293-1316.

19 De Jong EA, Ten Berge JCEM, Dwarkasing RS, Rijkers AP, Van Eijck $\mathrm{CHJ}$. The accuracy of MRI, endorectal ultrasonography, and computed tomography in predicting the response of locally advanced rectal cancer after preoperative therapy: A metaanalysis. Surgery. 2016;159(3): $688-99$

20. Kwok H, Bissett IP, Hill GL. Preoperative staging of rectal cancer. Int $J$ Colorectal Dis. 2000;15(1):9-20.

21. Morken JJ, Baxter NN, Madoff RD, Finne CO. Endorectal ultrasounddirected biopsy: A useful technique to detect local recurrence of rectal cancer. Int J Colorectal Dis. 2006;21(3):258-64. Epub 2005 Jun 8.

22. De Anda EH, Lee SH, Finne C0, Rothenberger DA, Madoff RD, GarciaAguilar J. Endorectal ultrasound in the follow-up of rectal cancer patients treated by local excision or radical surgery. Dis Colon Rectum. 2004; 47(6):818-24.

23. Sailer M, Bussen D, Fein M, Freys S, Debus SE, Thiede A, et al. Endoscopic ultrasound-guided transrectal biopsies of pelvic tumors. J Gastrointest Surg. 2002:6(3):342-6.

24. Drudi FM, Giovagnorio F, Raffetto N, Ricci P, Cascone F, Santarelli M, et al. Transrectal ultrasound color Doppler in the evaluation of recurrence of anal canal cancer. Eur J Radiol. 2003;47(2):142-8

25. Hünerbein M, Totkas S, Moesta KT, Ulmer C, Handke T, Schlag PM. The role of transrectal ultrasound-guided biopsy in the postoperative follow-up of patients with rectal cancer. Surgery. 2001;129(2):164-9.

26. Kolev NY, Tonev AY, Ignatov VL, Zlatarov AK, Bojkov VM, Kirilova TD, et al. The role of 3-D endorectal ultrasound in rectal cancer: Our experience. Int Surg. 2014:99(2):106-11.

27. Pinto RA, Corrêa Neto IJF, Nahas SC, Rizkalah Nahas CS, Sparapan Marques CF, Ribeiro Junior U, et al. Efficacy of 3-dimensional endorectal ultrasound for staging early extraperitoneal rectal neoplasms. Dis Colon Rectum. 2017:60(5):488-496.

28. Yahya JB, Farrell MJ, Herzig DO, Degnin CR, Chen Y, Holland J, et al. Preferential use of imaging modalities in staging newly diagnosed rectal cancer: a survey of US radiation oncologists. J Gastrointest Oncol. 2018; 9(3):435-440.

29. Memon S, Lynch AC, Bressel M, Wise AG, Heriot AG. Systematic review and meta-analysis of the accuracy of MRI and endorectal ultrasound in the restaging and response assessment of rectal cancer following neoadjuvant therapy. Colorectal Dis. 2015:17(9):748-61.

30. Morris OJ, Draganic B, Smith S. Does a learning curve exist in endorectal twodimensional ultrasound accuracy? Tech Coloproctol. 2011;15(3):301-11.

31. Li JCM, Liu SYW, Lo AWI, Hon SSF, Ng SSM, Lee JFY, et al. The learning curve for endorectal ultrasonography in rectal cancer staging. Surg Endosc. 2010:24(12):3054-9.

32. Kruskal JB, Kane RA, Sentovich SM, Longmaid HE. Pitfalls and Sources of Error in Staging Rectal Cancer with Endorectal US. Radiographics. 
1997;17(3):609-26.

33. Kim JC, Yu CS, Jung HY, Kim HC, Kim SY, Park SK, et al. Source of errors in the evaluation of early rectal cancer by endoluminal ultrasonography. Dis Colon Rectum. 2001;44(9):1302-9.

34. Carmody BJ, Otchy DP. Learning curve of transrectal ultrasound. Dis Colon Rectum. 2000;43(2):193-7.

35. Burtin JBP, Rabot AF, Heresbach D, Carpentier S, Rousselet MC, Le Berre N. Intraobserver Agreement in the Staging of Rectal Cancer Using Endoscopic Ultrasonography. Endoscopy. 1997;21(3):295-316.

36. De Gara CJ, Harpur G, Basrur V, North W, Knight P. The value of endorectal ultrasonography in the follow-up of intracavitary radiation treated early rectal cancer. Surg Oncol. 1995;4(1):15-9.

37. Scialpi M, Andreatta R, Agugiaro S, Zottele F, Niccolini M, Dalla Palma F et al. Rectal carcinoma: Preoperative staging and detection of postoperative local recurrence with transrectal and transvaginal ultrasound. Abdom Imaging. Fall 1993;18(4):381-9.

38. Kwakye G, Curran T, Uegami S, Finne 3rd CO, Lowry AC, Madoff RD, et al. Locally Excised T1 Rectal Cancers: Need for Specialized Surveillance Protocols. Dis Colon Rectum. 2019;62(9):1055-1062.

39. Park IJ, Kim JY, Yu CS, Lee JS, Lim SB, Lee JL, et al. Preoperative chemoradiotherapy for clinically diagnosed T3NO rectal cancer. Surg Today. 2016; 46(1):90-96. Epub 2015 Feb 25.

40. Löhnert MSS, Doniec JM, Henne-Bruns, D. Effectiveness of endoluminal sonography in the identification of occult local rectal cancer recurrences. Dis Colon Rectum. 2000;43(4):483-91.

41. Ross A, Rusnak C, Weinerman B, Kuechler P, Hayashi A, MacLachlan G, et al. Recurrence and survival after surgical management of rectal cancer. Am J Surg. 1999:177(5):392-5.

42. Novell F, Pascual S, Viella P, Trias M. Endorectal ultrasonography in the follow-up of rectal cancer. Is it a better way of to detect early local recurrence? Int J Colorectal Dis. 1997;12(2):78-81.

43. Rotondano G, Esposito P, Pellecchia L, Novi A, Romano G. Early detection of locally recurrent rectal cancer by endosonography. Br J Radiol. 1997; 70(834):567-71.

44. Hünerbein M, Dohmoto M, Haensch W, Schlag PM. Evaluation and biopsy of recurrent rectal cancer using three-dimensional endosonography. Dis Colon Rectum. 1996;39(12):1373-8.

45. Romano G, Esercizio L, Santangelo M, Vallone G, Santangelo ML. Impact of computed tomography vs. intrarectal ultrasound on the diagnosis, resectability, and prognosis of locally recurrent rectal cancer. Dis Colon Rectum. 1993;36(3):261-5.

46. Dresing K, Stock W. Ultrasonic endoluminal examination in the follow-up of colorectal cancer. Initial experience and results. Int J Colorectal Dis. 1990;5(4):188-94.

47. Beynon J, Mortensen NJ, Foy DM, Channer JL, Rigby H, Virjee J, et al. The detection and evaluation of locally recurrent rectal cancer with rectal endosonography. Dis Colon Rectum. 1989;32(6):509-17.

48. Mascagni D, Corbellini L, Urciuoli P, Di MG. Endoluminal ultrasound for early detection of local recurrence of rectal cancer. Br J Surg. 1989;76(11): 1176-80.

49. Hildebrandt U, Feifel G, Schwarz HP, Scherr O. Endorectal ultrasound: instrumentation and clinical aspects. Int J Colorectal Dis. 1986;1(4):203-7. 